\title{
Hypoxia in patients with acute hemiplegia
}

\author{
M J WALSHAW, M G PEARSON
}

\begin{abstract}
Sixteen patients with an early dense hemiplegia due to cerebrovascular accidents were shown to have a greater degree of hypoxia than 16 matched control patients. The patients with hemiplegia had a reflex compensatory fall in arterial carbon dioxide tensions $\left(\mathrm{PaCO}_{2}\right)$ with possible reduction in cerebral blood flow. Oxygen treatment led to an increase in $\mathrm{PaCO}_{2}$ in the patients with hemiplegia, but the increase in oxygen tensions in these patients was significantly less than that in the control group, suggesting increased pulmonary shunting as the cause for the hypoxia.
\end{abstract}

Oxygen treatment may improve cerebral blood flow and oxygenation and have a useful role in the early management of patients with a dense hemiplegia.

\section{Introduction}

Crude chest wall measurement ${ }^{1}$ and intercostal electromyographic studies ${ }^{2}$ have shown that ipsilateral dysfunction of respiratory muscles occurs after hemiplegia. This will cause hypoventilation of the lung on the affected side, but, in the acute stages at least, pulmonary perfusion may be normal. The inequality between ventilation and perfusion thus created will cause increased pulmonary shunting and consequent hypoxia. Hypoxia has been shown in convalescent patients with hemiplegia ${ }^{3}$ but no acute studies have been performed. In the present study arterial blood gas tensions were measured before and after oxygen treatment to establish whether pulmonary shunting and hypoxia are increased in early hemiplegia.

\footnotetext{
University Department of Medicine, Royal Liverpool Hospital, PO Box 147, Liverpool L69 3BX
}

M J WALSHAW, MB, MRCP, research fellow

Regional Adult Cardiothoracic Centre, Broadgreen Hospital, Liverpool L14 3LB

M G PEARSON, MA, MRCP, senior registrar

Correspondence to: $\mathrm{Dr} M \mathrm{~J}$ Walshaw.

\section{Patients and methods}

We studied patients with acute hemiplegia (hemiplegia that had occurred within the preceding 24 hours) in order to lessen the effect of reflex compensatory pulmonary mechanisms. Only those with dense hemiplegia (muscle power grade $1 / 5$ or less on Medical Research Council scale in both arm and leg on the affected side) were selected. Patients with an abnormality on chest $x$ ray examination or evidence of heart failure were excluded as they might already have had appreciable ventilation-perfusion mismatching. Those who may have had central respiratory dysfunction (patients with periodic breathing or altered consciousness) and those with cranial nerve palsies which suggested that the brain stem was affected were also excluded.

Patients with acute hemiplegia are usually admitted to hospital and are relatively immobile; for this reason controls were selected from a similar group of patients admitted to hospital with acute medical conditions. Patients who might have had appreciable ventilation-perfusion mismatching from an obvious cause were excluded-that is, patients with altered consciousness, any neurological disease, current heart failure, recent myocardial infarction, or an abnormality on chest $x$ ray examination.

We studied 16 consecutive patients with hemiplegia who fulfilled the criteria and compared them with 16 control patients who were well matched for age, sex, and smoking habits (table I). In the control

TABLE I-Matching of patients and controls

\begin{tabular}{lcc}
\hline & Patients with hemiplegia & Control patients \\
\hline Mean (SEM) age (years) & $65 \cdot 9(2 \cdot 9)$ & $66 \cdot 6(3 \cdot 3)$ \\
Sex & $7 \mathrm{M}, 9 \mathrm{~F}$ & $9 \mathrm{M}, 7 \mathrm{~F}$ \\
No of: & 10 & 9 \\
Smokers & 6 & 7 \\
Non-smokers & &
\end{tabular}

group five patients had minimal haematemesis with no evidence of cardiovascular or haematological embarrassment, four had osteoarthritis, two had cardiac arrhythmias with no evidence of heart failure, two had refractory hypertension with no evidence of heart failure, two had social problems, and one had inflammatory bowel disease. In the group. with hemiplegia nine patients had right and seven left hemiplegia. Five of these patients died within four weeks after presentation, all of whom had right hemiplegia. Most of the control group were admitted to hospital from the emergency department; all, however, had acute medical conditions and were chosen because of their immobility.

Resting samples for blood gas analysis were taken with a heparinised 
syringe from a femoral or radial artery and stored in crushed ice. The patient then breathed oxygen for 15 minutes through a Ventimask with the airholes taped up at a flow rate of $10 \mathrm{l} / \mathrm{min}$, giving an oxygen concentration of $59-65 \%$. Care was taken to ensure that the facemask fitted snugly on any patient with facial palsy. Arterial blood gas sampling was then immediately repeated. All blood samples were analysed within three minutes of sampling on the same self calibrating blood gas analyser (A B Lab II, Radiometer, Copenhagen), the autocalibration of which was checked daily.

\section{Results}

The patients with hemiplegia had a significantly greater degree of hypoxia at rest than the control group and showed a significantly lower rise in arterial oxygen tension $\left(\mathrm{PaO}_{2}\right)$ with administration of oxygen (table II, fig 1). They also had hypocapnia at rest when compared with the control patients, but after administration of oxygen they showed a significant rise in arterial carbon dioxide tension $\left(\mathrm{PaCO}_{2}\right)$ and the difference between the two groups disappeared (figs 2 and 3 , table II).

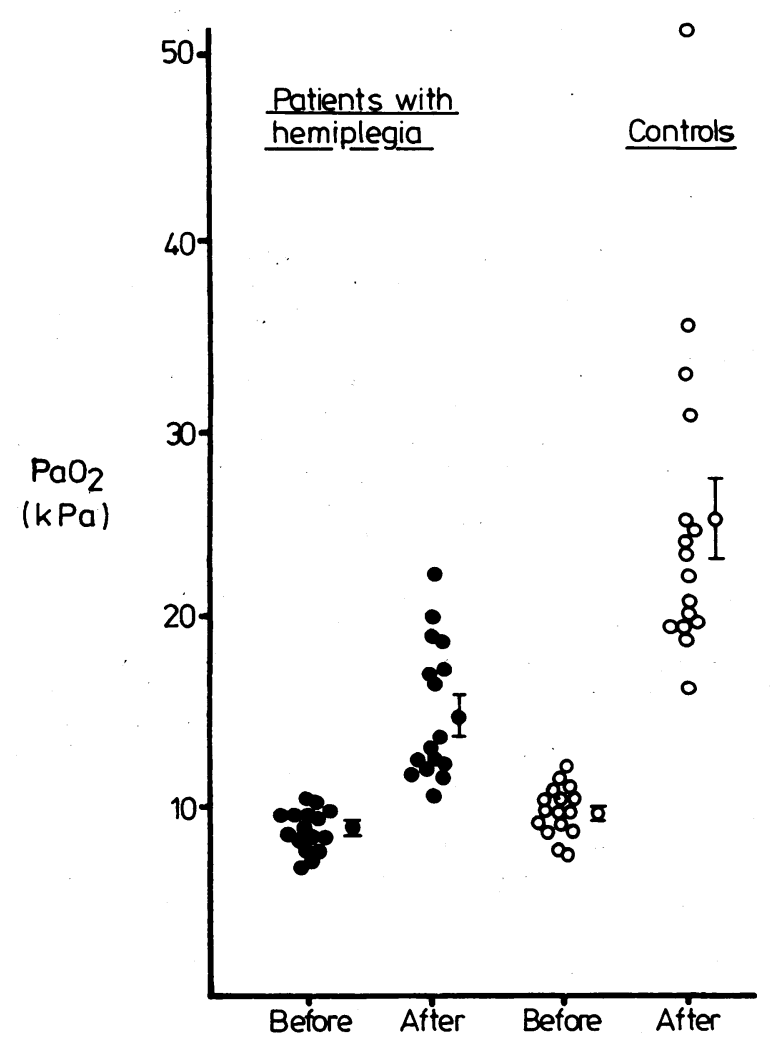

FIG 1-Arterial oxygen tensions $\left(\mathrm{PaO}_{2}\right)$ before and after administration of oxygen, with mean values (and SEM).

Conversion: $S I$ to traditional units- $\mathrm{PaO}_{2}: 1 \mathrm{kPa} \approx 7.5 \mathrm{~mm} \mathrm{Hg}$.

TABLE II-Results of blood gas analysis (means (SEM)) in patients with hemiplegia and controls

\begin{tabular}{|c|c|c|c|}
\hline & & At rest & After oxygen \\
\hline $\mathrm{PaO}_{\mathbf{2}}(\mathrm{kPa})$ & $\begin{array}{l}\text { Hemiplegia } \\
\text { Controls }\end{array}$ & $\begin{array}{ll}8.8 & (0.3)^{*} \\
9.8 & (0.3)\end{array}$ & $\begin{array}{ll}15.0 & (0.9)++ \\
25.3 & (2.2) t^{+}\end{array}$ \\
\hline $\mathrm{PaCO}_{2}(\mathbf{k P a})$ & $\begin{array}{l}\text { Hemiplegia } \\
\text { Controls }\end{array}$ & $\begin{array}{ll}4.5 & (0.2) * \\
5.3 & (0.1)\end{array}$ & $\begin{array}{ll}4 \cdot 8 & (0 \cdot 2) \S \\
5 \cdot 1 & (0 \cdot 2)\end{array}$ \\
\hline Bicarbonate (mmol/l) & $\begin{array}{l}\text { Hemiplegia } \\
\text { Controls }\end{array}$ & $\begin{array}{l}20.55(0.7) \\
22.65(1.1)\end{array}$ & $\begin{array}{l}20 \cdot 57(0.7) \\
22 \cdot 34(1 \cdot 0)\end{array}$ \\
\hline pH & $\begin{array}{l}\text { Hemiplegia } \\
\text { Controls }\end{array}$ & $\begin{array}{l}7.37(0.01) \\
7.37(0.01)\end{array}$ & $\begin{array}{l}7.35(0.01) \\
7.37(0.02)\end{array}$ \\
\hline
\end{tabular}

Significance of difference between values at rest and after oxygen: $t p<0.001$; $8 \mathrm{p}<0.01 ; \| \mathrm{p}<0.05$.

Significance of difference in values between control patients and those with hemiplegia: $\neq p<0.001 ; * p<0.01$.

Conversion: SI to traditional units- $\mathrm{PaO}_{2}$ and $\mathrm{PaCO}_{2}: 1 \mathrm{kPa} \approx 7.5 \mathrm{~mm} \mathrm{Hg}$. Bicarbonate: $1 \mathrm{mmol} / \mathrm{l}=1 \mathrm{mEq} / 1$
The serum bicarbonate concentration was lower in the group with hemiplegia than in the controls both before and after oxygen (fig 4). The $\mathrm{pH}$ was the same in both groups at rest but fell significantly in the group with hemiplegia after administration of oxygen.

All the data were analysed with Student's $t$ test, with the exception of $\mathrm{pH}$ and the change in $\mathrm{PaCO}_{2}$ after administration of oxygen, for which a Wilcoxon signed rank sum test was used.

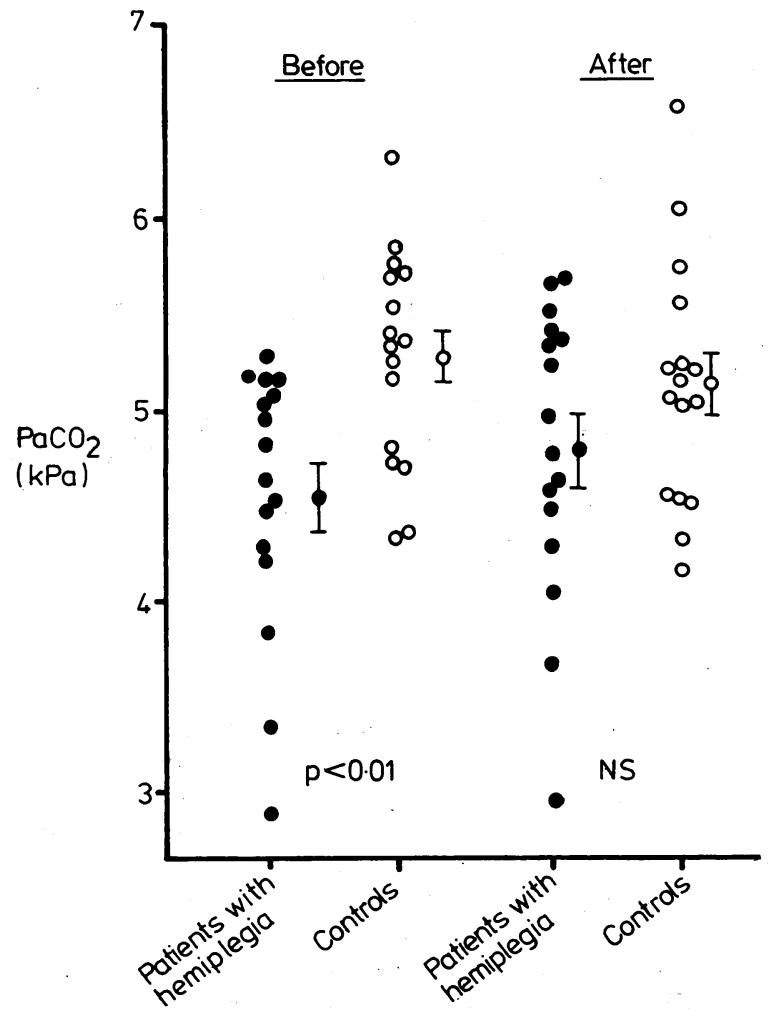

FIG 2-Arterial carbon dioxide tensions $\left(\mathrm{PaCO}_{2}\right)$ before and after administration of oxygen, with mean values (and SEM).

Conversion: $S I$ to traditional units- $\mathrm{PaCO}_{2}: 1 \mathrm{kPa} \approx 7.5 \mathrm{~mm} \mathrm{Hg}$.

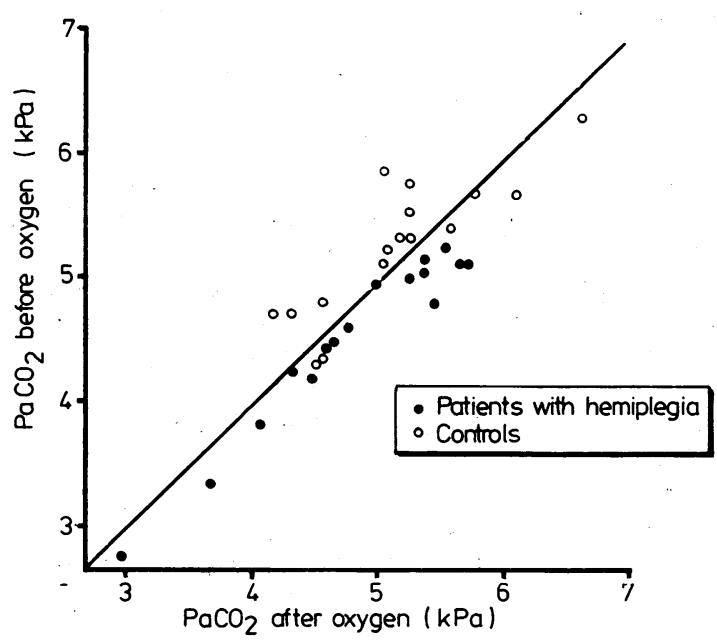

FIG 3-Relation between arterial carbon dioxide tensions $\left(\mathrm{PaCO}_{2}\right)$ before and after administration of oxygen.

Conversion: SI to traditional units- $\mathrm{PaCO}_{2}$ : $1 \mathrm{kPa} \approx 7.5 \mathrm{~mm} \mathrm{Hg}$.

\section{Discussion}

The initial hypoxia in the patients with hemiplegia and the poor response to oxygen are compatible with increased pulmonary shunting. Alveolar hypoventilation cannot have been the cause of the hypoxia because the hypocapnia recorded at rest indicated alveolar hyperventilation. Indeed, patients with 
acute hemiplegia often appear to have hyperventilation, and this has previously been attributed to a central neurogenic cause, ${ }^{4}$ with cerebral breakdown products stimulating the respiratory centre, or the brain stem having been directly

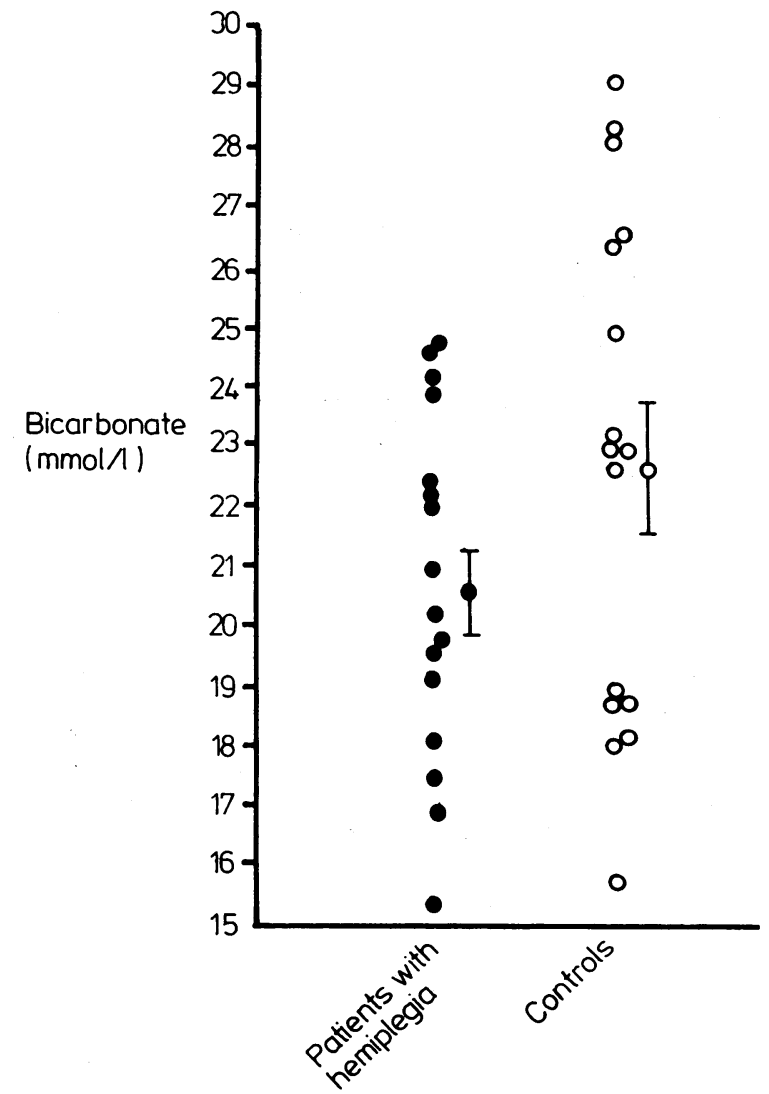

FIG 4-Serum bicarbonate concentrations before administration of oxygen.

Conversion: SI to traditional units-Bicarbonate: $1 \mathrm{mmol} / \mathrm{l}=$ $1 \mathrm{mEq} / \mathrm{l}$. piratory alkalosis, compensated for over a period of hours by a metabolic acidosis. This would be reflected in a lowered serum bicarbonate concentration, and such a tendency was found in our patients with hemiplegia. In such cases breathing oxygen should lessen the hyperventilation, leading to a temporary fall in $\mathrm{pH}$ (noted in our patients) until such time as the kidney can compensate. From these findings it is possible to construct a chain of events that occur after acute hemiplegia (fig 5).

We compared patients with hemiplegia with a control group of patients admitted to hospital with acute conditions, some of whom had considerable acidosis and hypoxia-features that may well reflect their degree of illness. The fact that we found a significant difference between these two groups suggests that we would have found larger differences if we had studied a healthy control population; most of the patients with hemiplegia would have fallen into such a group if studied the day before their admission.

Previous workers have shown that under conditions of stable hypoxia the $\mathrm{PaCO}_{2}$ falls in a predictable fashion with decreasing $\mathrm{PaO}_{2}{ }^{6}{ }^{7}$ Our control patients had hypoxia at rest with a normal $\mathrm{PaCO}_{2}$ (which did not change after treatment with oxygen), and this suggests that they were hypoventilating.

Our study has shown hypocapnia in patients with acute hemiplegia. Hypocapnia is a potent cause of vasoconstriction and can reduce cerebral blood flow by up to $35 \% .^{8}$ Alveolar hyperventilation can divert up to $30 \%$ of the cardiac output to the respiratory musculature, ${ }^{9}$ further depriving the cerebral circulation. In an acute vascular accident there may be a zone of oedematous and ischaemic but still potentially viable tissue around the area of infarction. Patients who have suffered an acute myocardial infarction are given oxygen treatment ${ }^{10}$ as an emergency measure in an attempt to reduce infarct size in the compromised area of myocardium, but administration of oxygen to a patient with dense hemiplegia in the first few hours of the illness is not routine. If these patients have hypoxia at rest they will benefit from oxygen treatment in three ways. Firstly, raising the $\mathrm{PaO}_{2}$ directly increases cerebral oxygenation. Secondly, as oxygen treatment relieves the hypoxic hyperventilation the hypocapnia will be lessened and cerebral vasodilatation will occur. Thirdly, the reduced demands of the respiratory musculature will allow more blood to supply the circle of Willis.

Attention to posture and administration of oxygen are simple procedures that might improve the prognosis of patients with acute hemiplegia.

We thank the physicians and patients of the Royal Liverpool Hospital who cooperated with this study, and also Dr C M Ogilvie for his invaluable help in the preparation of this paper.

\section{References}

1 Fluck DC, Chest movements in hemiplegia. Clin Sci 1966;31:383-8.

2 de Troyer A, de Beyl DZ, Thirion $M$. Function of the respiratory muscles in acute hemiplegia. Am Rev Respir Dis 1981;123:631-2.

${ }^{3}$ Haas A, Rusk HA, Pelosof H, Adam JR. Respiratory function in hemiplegic patients. Arch Phys Med Rehabil 1967;48:174-9.

4 Plum F, Swanson AG. Central neurogenic hyperventilation in man. AMA Archives of Neurology and Psychiatry 1959;81:535-48.

5 West JB, Glazier JB, Hughes JMB, Maloney JE. Recent work on the distribution of pulmonary blood flow and topographical difference in alveolar size. In: Cumming G, Hunt LB, eds. Form and function in the human lung. Edinburgh: Livingstone, 1968:111-24.

${ }^{6}$ Wolff CB. Normal respiration in chronic hypoxia. F Physiol 1980;303: 49-50P.

7 Cochrane GM, Prior JG, Wolff CB. Chronic stable asthma and the normal arterial pressure of carbon dioxide in hypoxia. $\mathrm{Br} \mathrm{Med} F 1980$; $281: 705-7$.

8 Raichle ME, Plum F. Hyperventilation and cerebral blood flow. Stroke 1972;3:566.

- Roussos C, Macklem PT. The respiratory muscles. N Engl f Med 1982; 307:786-97.

10 Anonymous. Oxygen in acute myocardial infarction [Editorial]. Lancet 1969 ;ii:525-6.

(Accepted 7 October 1983) 